\title{
A Guerra das Malvinas/Falkland revisitada, 1982: um estudo com fontes (militares) brasileiras
}

\author{
Carlos Federico Dominguez Avila*
}

\section{RESUMO}

O artigo examina as percepçôes e interpretaçôes de assessores do ministro do Exército brasileiro contidas em um conjunto de relatórios sobre o conflito militar anglo-argentino no Atlântico Sul, entre abril e junho de 1982. A pesquisa enfoca três tópicos: uma aproximação ao conflito sob a perspectiva Oeste-Oeste, a dimensão latino-americana do conflito, e as implicaçóes de uma mudança de regime político na Argentina decorrente da derrota no conflito. $\mathrm{O}$ ensaio de interpretação sugere que a pesquisa acadêmica com documentos militares é particularmente significativa quando o problema-objeto é correlacionado aos temas de segurança e defesa.

Palavras-chave: segurança internacional; Reino Unido; Argentina; defesa; Guerra das Malvinas/Falkland.

\section{The Falkland War Reviewed, 1982: an essay with Brazilian (military) sources}

\section{ABSTRACT}

This paper examines the perceptions and interpretations of advisers to the Brazilian Army Minister contained in a set of reports on the Anglo-Argentine military conflict in the South Atlantic, which occurred between April and June 1982. It focuses on three topics related to the conflict: the West-West perspective, the Latin American dimension, and the implications of the change in political regime in Argentina as a result of defeat. This interpretation suggests that academic research with military documents is particularly useful when dealing with the subjects of security and defense.

Keywords: international security; United Kingdom; Argentina; defense; Falkland War.

\section{DOI: http://dx.doi.org/10.1590/2237-101X02204711}

Artigo recebido em 19 de julho de 2020 e aceito para publicação em 11 de setembro de 2020.

* Pesquisador da Universidade de Brasília, Departamento de Estudos Latino-Americanos, Brasília/DF - Brasil. E-mail: cdominguez_unieuro@yahoo.com.br. ORCID: https://orcid.org/0000-0003-2377-276X. 


\section{La Guerra de las Malvinas/Falkland revisada, 1982: un estudio con fuentes (militares) brasileñas}

\section{RESUMEN}

El artículo examina las percepciones e interpretaciones de asesores del ministro del Ejército brasileño contenidas en un conjunto de informes sobre el conflicto militar anglo-argentino en el Atlántico Sur en abril y junio de 1982. La investigación se enfoca en tres tópicos: una aproximación al conflicto sobre la perspectiva Oeste-Oeste, la dimensión latinoamericana del conflicto y las implicaciones de un cambio de régimen político en Argentina consecuencia de la derrota en el conflicto. El ensayo de interpretación sugiere que la investigación académica con documentos militares es particularmente significativa cuando el problema-objeto es correlacionado a los temas de seguridad y defensa.

Palabras clave: Seguridad Internacional; Reino Unido; Argentina; Guerra de las Malvinas/ Falkland.

\section{Introdução}

Em 2 de abril de 1982, por volta de 600 fuzileiros navais e efetivos do exército argentino realizaram atos possessórios no arquipélago das Malvinas/Falkland. O operativo militar argentino também ocorreu nas ilhas Geórgia do Sul e Sandwich do Sul. Logo de uma resistência simbólica do contingente militar britânico, o governador Rex Hunt negociou uma rendição. E em poucas horas os representantes político-administrativos britânicos retornaram ao Reino Unido. Sob a perspectiva argentina, os atos possessórios poderiam ser gradualmente substituídos pela realização de negociaçóes diplomáticas bilaterais ou multilaterais, desde que orientadas a confirmar a soberania desse país nos territórios em disputa. Contudo, a reação britânica, encabeçada pelo governo da primeira-ministra Margaret Thatcher acabou sendo muito vigorosa. Uma força-tarefa foi organizada com o intuito de reconquistar as ilhas. Daí que em poucos dias as partes se declarassem em Estado de Guerra, fossem impostas zonas de exclusão em volta do arquipélago e vultosos dispositivos militares fossem implementados (ALEIXO, 1991). Observe-se que se tratava do primeiro operativo de grande porte impulsionado tanto pelos ingleses desde o fim da Segunda Guerra Mundial quanto pelos argentinos desde a guerra da Tríplice Aliança contra o Paraguai (1864-1870). Assim, entre 2 de abril e 14 de junho uma série de combates aeronavais e terrestres resultaram na rendição das forças argentinas no denominado teatro de operaçôes do Atlântico Sul. Durante os combates morreram 649 militares argentinos, 255 
britânicos e três habitantes civis das ilhas em disputa (VERBITSKY, 2002; BRATTON; THIES, 2011; MUÑOZ, 1984).

Nesse contexto, o objetivo do presente ensaio de interpretação é examinar as percepçôes e interpretaçóes contidas numa coleção de documentos intitulada Sumário Diário de Informaçôes - doravante denominados simplesmente de Sumários. ${ }^{1}$ Os referidos relatórios foram preparados pelos assessores do entáo ministro do Exército brasileiro Walter Pires de Carvalho e Albuquerque, e versam acerca da evoluçáo e dos eventuais desdobramentos gerais desse conflito anglo-argentino. Com efeito, as fontes primárias que fundamentam a presente contribuição são um conjunto de 55 relatórios preparados para o gabinete do ministro, com o intuito de lhe informar sobre os acontecimentos no teatro de operaçóes militares, assunto particularmente relevante na pasta sob sua responsabilidade - e tudo isso no marco do governo comandado pelo general João Batista de Oliveira Figueiredo (1979-1985).

O conjunto de Sumários que são objeto desta pesquisa foram redigidos, quase diariamente, entre 12 de abril e $1^{\circ}$ de julho de 1982. A difusão inicial desse conjunto de relatórios era restrita aos órgãos superiores do Ministério do Exército - daí que a maioria deles fosse considerada confidencial ou secreta. Contudo, uma cópia dos referidos documentos foi regularmente encaminhada à Secretaria-Geral do Conselho de Segurança Nacional doravante SG/CSN. Com o passar do tempo, boa parte da documentação desta última entidade - inclusive a documentação ora utilizada como fonte primária - foi transferida à Coordenação Regional do Arquivo Nacional no Distrito Federal. Todavia, o denominado Acervo da Secretária Geral do Conselho de Segurança Nacional acabou sendo digitalizado e disponibilizado para consulta e pesquisa como arquivo eletrônico. Em consequência, a presente pesquisa foi realizada com base em documentação disponibilizada pelo Arquivo Nacional - no sucessivo SG/CSN/AN.

Cumpre destacar que os Sumários em referência foram objeto da correspondente e imprescindível crítica documental de fontes primárias. No que diz respeito à crítica interna da documentaçấo constatou-se que os Sumários em apreciação são originais, verídicos e consistentes. Em outras palavras, trata-se de fontes primárias legítimas, válidas e confráveis para a realização de uma pesquisa em segurança e defesa, em relaçôes internacionais ou em história militar.

De modo geral, os Sumários em questáo apresentam uma idiossincrasia e um estilo de redação fortemente burocrático, no sentido weberiano do termo. Trata-se, como dito, de relatórios preparados por subordinados - especificamente por oficiais da $1^{\text {a }}$ Subchefia do Ministério do Exército - para o gabinete do Ministro Walter Pires. Na maioria das

\footnotetext{
${ }^{1}$ Sumário Diário de Informaçôes n. 5-E2.1/EME (Confidencial), 12.4.1982. Brasília: Ministério do Exército, Acervo da Secretaria Geral do Conselho de Segurança Nacional, Coordenação Regional do Arquivo Nacional no Distrito Federal - doravante SG/CSN/AN.
} 
vezes os documentos incluem duas partes, a primeira, denominada de Situação, descreve acontecimentos em curso; e a segunda, chamada de Apreciação, faz uma análise interpretativa daqueles acontecimentos. Evidentemente, a parte da Apreciação é particularmente relevante para os fins deste estudo. Outrossim, surpreendeu ao autor deste ensaio de interpretação a isenção, pragmatismo, equanimidade, pulcritude, razoabilidade e profissionalismo do trabalho realizado pelos assessores para o comandante do Exército. Daí que, com raríssimas exceçóes, não pareça ser oportuno nem apropriado admitir desqualificaçôes das fontes primárias por eventuais motivaçôes ou preferências ideológicas, burocrático-autoritárias ou similares.

Em relação à crítica externa da documentação, entende-se e confirma-se que as fontes primárias consultadas são convergentes e atinentes ao problema-objeto deste estudo. Isto é, os Sumários efetivamente contribuem na análise das percepçóes e interpretações de parte significativa do estamento político-militar brasileiro - comandado pelo general Figueiredo em relação ao conflito anglo-argentino no Atlântico Sul (SANTOS, 2016; LAFER, 1984). Em consequência, parece evidente que as fontes têm aderência à pesquisa em andamento, aos acontecimentos históricos - isto é, ao conflito militar anglo-argentino propriamente dito - e à literatura especializada na temática em questáo tanto brasileira quanto estrangeira. Assim, mais que cotejar a descrição dos acontecimentos observados pelas testemunhas da época - inclusive pelas aditâncias militares brasileiras lotadas nos países com vínculos e interesses no conflito -, o presente artigo procura avançar no debate acadêmico sobre a temática a partir de uma pesquisa historiográfica com fontes primárias.

A estrutura interna do artigo inclui três partes sobre assuntos que, salvo melhor interpretação, acabaram configurando-se como os mais transcendentes no processo de ampliação, aprimoramento e aprofundamento do conhecimento disponível, notadamente na literatura brasileira acerca do conflito militar anglo-argentino. Na primeira parte aborda-se o conflito militar num contexto global e bipolar. $\mathrm{Na}$ parte seguinte são auscultadas as percepçôes e interpretaçôes dos oficiais brasileiros acerca dos desígnios e diretrizes de outras potências latino-americanas com vínculos e interesses no problema-objeto. E, finalmente, resgatam-se elucubraçôes e implicaçóes da derrota militar argentina sob a perspectiva da mudança de regime político - ou uma democratização precoce - e suas possíveis implicaçôes nas relaçôes bilaterais brasileiro-argentinas. 


\section{Galtieri, Thatcher, Reagan e Brejnev no Atlântico Sul: um conflito Oeste-Oeste?²}

Para além da teoria realista ou da teoria do imperialismo, o conflito anglo-argentino no Atlântico Sul foi, essencialmente, uma disputa territorial militarizada entre dois Estados (MARES; BERNSTEIN, 1998; DAVID, 2001; WALTZ, 1979). Mesmo que não houvesse uma declaração formal de guerra ou uma escalada incontrolada das açóes militares entre as partes - isto é, uma guerra total -, ambos os governos anunciaram a existência de um estado de beligerância, que resultou em ataques recíprocos, desde os atos possessórios argentinos até a vitória militar britânica (abril-junho de 1982). A esse respeito, em 15 de abril de 1982, bem no início do conflito, foi ponderado e vislumbrado, por exemplo, o seguinte:

Apesar de sua evidente superioridade qualitativa e quantitativa, a esquadra britânica encontrará dificuldades para sobrepor-se à armada argentina, caso haja confronto entre as forças dos dois países, em virtude da superioridade aérea local argentina.

No caso de uma batalha naval, devem ser consideradas as grandes dificuldades logísticas para abastecimento da esquadra inglesa, em contraposição à facilidade de apoio com que poderá contar a Armada argentina, em face da proximidade das Ilhas MALVINAS do continente.

A hipótese de um desembarque inglês nas Ilhas MALVINAS vai ficando mais remota, tendo em vista a quantidade de meios terrestres que a ARGENTINA já colocou na área, bem como os preparativos para a defesa que vêm sendo realizados, desde o primeiro dia de ocupação.

Por outro lado, a quantidade de meios humanos e materiais que a Força-Tarefa britânica transporta poderia pressupor um possível desembarque nas Ilhas GEÓRGIA DO SUL, conseguindo com isso uma base de apoio, reduzindo a vantagem argentina proporcionada pela posição geográfica de seu território. ${ }^{3}$

\footnotetext{
${ }^{2}$ Com relação aos assim chamados conflitos Oeste-Oeste no contexto da competição, tensão e confrontação do período da Guerra Fria, parece pertinente ponderar que alguns conflitos entre países do bloco capitalista efetivamente chegaram a ter grande relevância teórica e empírica. Fred Halliday (1986) pondera que os teóricos dos conflitos Oeste-Oeste incluíam, de um lado, os esforços da principal potência do bloco ocidental - isto é, dos Estados Unidos - para disciplinar e alinhar seus parceiros e/ou satélites. De outro, existiram contradiçôes entre certas potências capitalistas - como a França gaullista - e o bloco político-militar da Otan. Outrossim, uma terceira categoria de conflitos Oeste-Oeste foi acerca de disputas territoriais ou limítrofes militarizadas entre potências com governos de orientação ocidental como o anglo-argentino pelas Malvinas/ Falkland, o greco-turco no mar Egeu e no Chipre, o confronto fronteiriço entre Indonésia e Malásia, ou o confronto entre o Irã e os Emirados Árabes Unidos pelas ilhas Tunb (no Golfo Pérsico). Todavia, também existiram alguns conflitos Este-Este; eis os casos dos confrontos fronteiriços e ideológicos entre a União Soviética e China (na região do rio Ussuri), entre a China e o Vietnã, entre a Albânia e a Iugoslávia, e entre o Vietná e o Camboja.

${ }^{3}$ Sumário Diário de Informaçôes n. 8-E2.1/EME (Confidencial), 15.4.1982. Brasília: Ministério do Exército, SG/CS/AN.
} 
Todavia, o conflito militar anglo-argentino coincidiu cronologicamente com uma época de recrudescimento das tensôes globais, inclusive no sentido bipolar - isto é, na competição Leste-Oeste ou Guerra Fria. Mais especificamente, o conflito das Malvinas/Falkland coincidiu com o que Fred Halliday (1986) chamou de Segunda Guerra Fria, vigente entre a ocupação soviética do Afeganistão em 1979 e a queda do muro de Berlim/implosão da própria União Soviética em 1989/91. ${ }^{4}$ Efetivamente, em 1982 as tensões Leste-Oeste formavam parte do cálculo estratégico dos principais atores com vínculos e interesses na questão das ilhas do Atlântico Sul, dentre eles os governos do argentino Leopoldo Galtieri (1981-1982), da britânica Margaret Thatcher (1979-1990), do estadunidense Ronald Reagan (1981-1989), do soviético Leonid Brejnev (1964-1982) e do brasileiro João B. Figueiredo (1979-1985).

A questáo da bipolaridade rígida no sentido Leste-Oeste é significativa para os fins deste estudo porque os autores dos Sumários ao ministro do Exército brasileiro expressaram reiteradamente um grande receio de uma eventual aproximação da Argentina de Galtieri à União Soviética de Brejnev, na esteira de uma provável derrota militar no teatro de operações do Atlântico Sul. Isolados e sujeitados a um embargo de transferência de armas de fabricação ocidental, os assessores do ministro do Exército brasileiro alertaram sobre uma eventual - e até paradoxal - "expansão do comunismo" naquele país vizinho do Brasil. Considere-se, por exemplo, a seguinte ponderação: "países do bloco comunista procuram exercer uma maior influência na evolução dos acontecimentos. A posição dos soviéticos e seus aliados enquadra-se na estratégia de expansão do comunismo." $\mathrm{O}$ assunto pode parecer contraditório, já que pouco antes do desembarque anfíbio argentino nas ilhas em disputa, tanto o governo conservador de Thatcher quanto o regime burocrático-autoritário de Galtieri estavam entre os mais firmes aliados anticomunistas da neoglobalista administração Reagan na Europa Ocidental e no Cone Sul, respectivamente - sentimento anticomunista que também era compartilhado pelo estamento político-militar imperante no Brasil (SANTOS, 2016; RUSSELL, 1988).

É bastante provável que no cálculo estratégico e no planejamento argentino que resultou na ocupação das ilhas do Atlântico Sul - denominado de operativo Rosário -, uma benevolente, condescendente e equidistante neutralidade da administraçáo Reagan tivesse sido imaginada. Afinal, na época dos fatos, o governo de Galtieri estava colaborando ativamente em atividades antissubversivas na América Central e nos Andes - especialmente no Peru e na Bolívia -, tudo isso atendendo à solicitação expressa de Washington. Assessores militares argentinos também colaboraram ativamente na criação das forças contrarrevolucionárias patrocinadas pelos Estados Unidos contra a Nicarágua sandinista (ARMONY, 1999).

\footnotetext{
${ }^{4}$ De fato, o conflito anglo-argentino no Atlântico Sul coincidiu com a fase de bipolaridade rígida da Segunda Guerra Fria, isto é, no subperíodo entre 1979 e 1985 (HALLIDAY, 1986). Uma fase de bipolaridade flexível verificou-se a partir da chegada ao poder do secretário-geral Mikhail Gorbachëv, entre 1985 e 1989/91.

${ }^{5}$ Sumário Diário de Informações n. 7-E2.1/EME (Confidencial), 14.4.1982. Brasília: Ministério do Exército, SG/CSN/AN.
} 
Igualmente, a administração Reagan tinha recentemente suspenso os embargos impostos à Argentina durante a presidência de James Carter; e o próprio Galtieri era considerado como um dos oficiais mais favoráveis aos Estados Unidos nas forças armadas do país sul-americano. Em outras palavras, no marco dos atos possessórios argentinos no Atlântico Sul, pressupunha-se que a administração Reagan poderia tentar apaziguar a reação do tradicionalíssimo aliado britânico (LEBOW, 1983).

Como quer que seja, também é importante ponderar que mesmo durante os violentos e repressivos governos do assim chamado Processo de Reorganização Nacional, vigente desde março de 1976, e apesar da feroz retórica antimarxista (NOVARO; PALERMO, 2007), sucessivos governos militares argentinos mantiveram relaçóes pragmáticas com os soviéticos, sob a hipótese de alguma vinculação entre a continuidade de massivas exportaçôes de cereais argentinos, de um lado, e alguma segurança para a elite dirigente do Partido Comunista da Argentina (VACS, 1984; RAPOPORT, 1988). Ainda que no início dos atos possessórios que resultaram na ocupação das ilhas ninguém imaginasse uma interdependência ou numa penetração comunista na Argentina de Galtieri, no mesmo dia 2 de abril o embaixador soviético foi convidado para uma reuniáo na Casa Rosada, com intuito de examinar as relaçóes bilaterais e multilaterais entre as partes num contexto transformado. A esse respeito, as fontes constataram, por exemplo, o seguinte:

O regime político vigente na ARGENTINA vem sendo alvo, desde a sua implantação, de violenta campanha de desmoralização, no exterior. Dessa campanha, têm participado correntes esquerdistas de diversas colorações. Após a eclosão da crise das ILHAS MALVINAS, não só os grupos esquerdistas radicais da ARGENTINA passaram a apoiar o Governo de BUENOS AIRES. Idêntica postura, assumiram as esquerdas em outros países, o que indica a existência de orientação externa para tal procedimento, principalmente considerando a definição da URSS e seus satélites sobre a crise no ATLÂNTICO SUL.

Por outro lado, independentemente de ideologia, em vários países americanos, o BRASIL incluído, têm surgido grupos de apoio à posição da ARGENTINA. ${ }^{6}$

A partir de abril de 1982, as fontes consultadas constataram com insistência e preocupação os contatos e a incipiente coordenação argentino-soviética. Propaganda favorável ao governo burocrático-autoritário argentino passou a ser transmitida em diferentes meios de comunicação controlados direta ou indiretamente pelos soviéticos. Os partidos comunistas e a maioria das organizaçóes de esquerda ibero-americana e afro-asiática também adotou

\footnotetext{
${ }^{6}$ Sumário Diário de Informações n. 12-E2.1/EME (Confidencial), 22.4.1982. Brasília: Ministério do Exército, SG/CSN/AN.
} 
uma perspectiva anticolonialista e anti-imperialista - isto é, antibritânica e antiamericana (KREPP, 2017).

Outrossim, em aparente troca de iniciativas, o governo de Buenos Aires autorizou um gradual retorno de exilados e a libertação de um grande número de prisioneiros políticos - em sua maioria sindicalistas, esquerdistas e peronistas -; além de reiterar a segurança pessoal da elite do Partido Comunista Argentino. E mesmo que dificilmente os soviéticos entrassem em uma escalada contra o Reino Unido e/ou os Estados Unidos em função da crise no Atlântico Sul, certamente Moscou, Havana e simpatizantes tentaram explorar a disputa territorial entre duas importantes potências ocidentais - uma europeu-ocidental e outra latino-americana. Eis o surgimento de um conflito Oeste-Oeste, comparável a outros vigentes no cenário bipolar da Guerra Fria, como por exemplo o greco-turco.

A convergência da Argentina com a União Soviética era simultânea e paralela ao insatisfatório resultado dos esforços de mediação impulsionados pela administração Reagan e realizados pelo secretário de Estado Alexander Haig. Nesses esforços diplomáticos, o secretário Haig fez numerosas viagens a Londres e Buenos Aires tentando construir uma saída negociada, pacífica e que pudesse preservar o consenso estratégico anticomunista no Atlântico Sul (ROETT, 1984). Cumpre acrescentar que esses esforços diplomáticos estadunidenses no conflito anglo-argentino foram positivamente avaliados pelas fontes primárias consultadas - isto é, pelos assessores do ministro do Exército brasileiro. Como quer que seja, também existia a possibilidade do fracasso dos esforços de Haig. Nessa esteira, parece pertinente considerar, por exemplo, a seguinte ponderação:

A questão bilateral entre ARGENTINA e INGLATERRA poderá enfraquecer a liderança dos EUA e ameaçar a própria segurança do ocidente.

Caso a INGLATERRA, após ter enviado contra a ARGENTINA a maioria do seu poderio naval convencional, não consiga recuperar o controle do arquipélago, a OTAN sofreria considerável perda de credibilidade.

Por outro lado, um desfecho desfavorável à ARGENTINA, criaria um clima de insatisfação e desconfiança da maioria dos países latino-americanos, em relação aos países desenvolvidos do mundo ocidental.

Com efeito, as posiçóes das partes em conflito eram muito distantes, intransigentes e inflexíveis. A questão da soberania estatal nas ilhas era reivindicada firme e categoricamente por britânicos e argentinos, com argumentos jurídicos, estratégicos e históricos

\footnotetext{
${ }^{7}$ Sumário Diário de Informaçôes n. 7-E2.1/EME (Confidencial), 14.4.1982. Brasília: Ministério do Exército, SG/CSN/AN.
} 
(LIVINGSTONE, 2020; MARGHERITIS, 1991). Sob a perspectiva inglesa, antes de iniciar quaisquer negociaçóes, as forças argentinas deveriam abandonar as ilhas do Atlântico Sul e a administraçâo britânica deveria ser restaurada. Para os argentinos, as negociaçôes eram possíveis, desde que orientadas a reconhecer a sua soberania naqueles territórios. Destarte, no final de abril, a administração Reagan anunciou o seu apoio aos ingleses, especialmente em termos político-diplomáticos, logísticos e de inteligência. Igualmente, Washington julgou necessário reimpor um embargo econômico e de transferência de material de emprego militar de fabricação norte-americana para o país sul-americano (ORREGO VICUÑA, 1984). No campo multilateral, o governo dos Estados Unidos negou-se e refutou categoricamente as alegaçóes argentinas em favor da ativação do Tratado Interamericano de Assistência Recíproca, bem como de iniciativas argentinas de semelhante teor no Conselho de Segurança da Organização das Naçóes Unidas ou na Organização dos Estados Americanos (JAGUARIBE, 1985). O isolamento argentino das principais potências ocidentais também se observou nos embargos impostos pelos países membros da Comunidade Econômica Europeia e da Comunidade das Naçóes - Commonwealth of Nations - agrupamento integrado fundamentalmente pelas ex-colônias britânicas em diferentes continentes. $\mathrm{O}$ anúncio do apoio estadunidense a Londres, em 30 de abril de 1982, motivou a seguinte Apreciação:

A posição assumida pelos EUA coloca a ARGENTINA em difícil situação.

Isto aumenta o risco de uma aproximaçáo com a URSS e do estabelecimento de um acordo de assistência militar com aquele país, ao mesmo tempo em que afasta a ARGENTINA, cada vez mais, do bloco ocidental.

Um maior envolvimento da URSS no conflito traz para a vizinhança do território brasileiro os perigos de um conflito de caráter mundial. ${ }^{8}$

Nessas circunstâncias, os assessores do ministro do Exército não deixaram de externalizar a preocupação pelo rápido isolamento dos argentinos no contexto dos países ocidentais e a crescente dependência do governo de Galtieri em relação aos soviéticos e a governos de outros países críticos do bloco ocidental - especialmente da Líbia de Muammar al-Gaddafi e do Iraque de Saddam Hussein. Uma eventual "expansão do comunismo" a partir de uma guinada político-ideológica encabeçada pelo Galtieri, da formaçáo de um governo de emergência nacional, de uma assonada golpista, ou de uma tomada do poder por emergentes núcleos pró-soviéticos, peronistas ou radicais no país vizinho passaram a ser hipóteses muito seriamente consideradas pelos autores dos Sumários, principalmente a partir do desembar-

\footnotetext{
${ }^{8}$ Sumário Diário de Informaçôes n. 18-E2.1/EME (Confidencial), 30.4.1982. Brasília: Ministério do Exército, SG/CSN/AN.
} 
que anfíbio de tropas inglesas, em 21 de maio de 1982, na ilha Soledade - ou Malvina oriental, local onde se encontra a capital do arquipélago Stanley ou Porto Argentino - e de uma provável recomposição do status quo ante bellum.

Agora se sabe que, com o propósito de agudizar o conflito anglo-argentino no sentido Oeste-Oeste, os soviéticos mobilizaram recursos de inteligência, fizeram intermediação junto a governos críticos do Ocidente e implementaram uma campanha propagandística de forte conotação anti-imperialista, anticolonialista e favorável à causa nacionalista argentina (ESCUDÉ, 1988; VACS, 1984). "A aproximação ARGENTINA-URSS, associada à necessidade do Governo argentino obter coesão interna, permite admitir a possibilidade de alguma alteração ideológica no atual regime argentino", lê-se num dos relatórios sob apreciação. ${ }^{9}$ Todavia, as fontes primárias consultadas sugerem que assessores militares e material de emprego militar de fabricação soviética - especificamente um sistema de radares de longa distância teriam sido observados em território argentino no final de maio e no início de junho de 1982. E, na última semana do conflito militar, as fontes ainda alertavam o seguinte:

A obtenção de uma paz negociada continua difícil, tendo em vista que ambas as partes mantêm a mesma posição de intransigência adotada desde o início do conflito.

Um maior compromisso argentino com a URSS poderá ter consequências imprevisíveis para o atual Governo, não só na política interna, como também, no que diz respeito ao seu relacionamento com os demais países da AMERICA DO SUL, especialmente com seus vizinhos. $^{10}$

Procurando evitar uma humilhaçáo completa e total das forças armadas e do regime burocrático-autoritário argentino, Washington pressionou Londres nos últimos dias do conflito. Buscava-se um compromisso britânico de não ultrajar ou comprometer gravemente os "brios nacionais argentinos" (TULCHIN, 1986). E, diante da intransigência de Galtieri, que, pouco antes da assinatura da rendição dos soldados argentinos em Malvinas/Falkland, especulou com a continuidade do conflito - inclusive com a ampliação do teatro de operaçóes militares a todo o território continental do país -, somente a queda do presidente-general, em 17 de junho de 1982, tranquilizou aos assessores do ministro Walter Pires. Paradoxalmente, de forma gradual, o espantalho da "sovietização" deu lugar ao fantasma da "democratização" do vizinho argentino, assunto que é tratado em parte subsequente deste ensaio de interpretação.

\footnotetext{
${ }^{9}$ Sumário Diário de Informaçóes n. 15-E2.1/EME (Confidencial), 27.4.1982. Brasília: Ministério do Exército, SG/CSN/AN.

${ }^{10}$ Sumário Diário de Informações n. 44-E2.1/EME (Confidencial), 9.6.1982. Brasília: Ministério do Exército, SG/CSN/AN.
} 


\section{A dimensão latino-americana do conflito: contradiçóes e vicissitudes peruanas}

Durante as dez semanas do confronto militar anglo-argentino houve numerosas referências nas fontes primárias consultadas aos países latino-americanos com maiores vínculos e interesses no conflito, especialmente em relação ao peculiar caso peruano (MONETA, 1984). Em geral, os governos latino-americanos e caribenhos se posicionaram de forma neutral - ou mais exatamente com uma neutralidade benevolente para o lado argentino. As reivindicaçôes inglesas de soberania nas ilhas do Atlântico Sul tiveram alguma ressonância nas ex-colônias britânicas do Caribe - principalmente em Trindade e Tobago, Guiana e Belize -, no Chile do general Augusto Pinochet - em virtude de disputas territoriais com a Argentina, bem como com o Peru e a Bolívia - e possivelmente na Colômbia (PHILIP, 1985). Entretanto, os governos do Brasil, do Peru, da Venezuela, do Uruguai, da Guatemala, de Cuba, da Nicarágua e da maioria dos outros países do continente latino-americano manifestaram publicamente - em termos bilaterais e multilaterais - uma neutralidade mais ou menos simpática aos argentinos.

Para os fins deste artigo, parece relevante ponderar que as fontes primárias consultadas revelaram certa preocupaçáo com a surpreendente, persistente e intensa cooperação militar do Peru - ou mais exatamente do alto comando militar peruano - com a Argentina de Galtieri. Observe-se que a referida cooperaçáo militar do Peru com a Argentina aparentemente não era aprovada pelo presidente do país Fernando Belaúnde Terry. Fontes primárias e secundárias sugerem que o comprometimento peruano-argentino era iniciativa especificamente do ministro da Guerra, general Luis Federico Cisneros Vizquerra. Considere-se, por exemplo, a seguinte referência:

No PERU, canais de televisão, no dia 20 Mai 82, divulgaram declaraçóes do Pres BELAÚNDE TERRY a respeito da proposta peruana de paz, argumentando ser necessário um cessar-fogo imediato, a fim de evitar perdas humanas e materiais. Esta posição foi repetida no dia $23 \mathrm{Mai}$ 82 , quando declarou, textualmente, haver recomendado a todas as chancelarias peruanas e aos Ministérios das Forças Armadas, que a política do PERU é apoiar o cessar-fogo e a obtenção de uma paz negociada, acrescentando que o país não poderia abrir mão de seu material bélico, sem colocar em risco a segurança nacional. Deu ênfase à missão do PERU, que considera "mais importante como gestor da paz, que como participante em armas".

No mesmo dia 20, após as declaraçóes do Pres BELAÚDE, as televisóes entrevistaram ao vivo o Gen [LUIS] CISNEROS, Ministro da Guerra, que se declarou favorável a um imediato apoio militar peruano à ARGENTINA, embora ressalvando, entretanto, que o assunto é da competência do Presidente da República e do Congresso Nacional. 
[...] Observa-se nítida divergência de opiniāo a respeito da crise das MALVINAS, entre o Pres BELAÚNDE TERRY e o Gen CISNEROS, Ministro da Guerra do PERU.

O Gen CISNEROS poderia estar, assim, buscando melhor liderança no Exército Peruano, já que este mantém estreitos laços com as Forças Armadas Argentinas. ${ }^{11}$

Luis Federico Cisneros Vizquerra nasceu em Buenos Aires e morou na Argentina até os 22 anos de idade. Na época, seu pai - um reconhecido escritor peruano - estava exilado. Segundo o relato autobiográfico de seu filho, Renato Cisneros (2015), El Gaucho Cisneros se formou como cadete da Escola Superior de Guerra argentina na mesma promoção de Galtieri e de Jorge Videla. Após o retorno de sua família ao Peru, Cisneros ascendeu rapidamente na hierarquia militar peruana, mantendo ao longo do tempo uma forte vinculação profissional e afetiva com seus ex-colegas argentinos e com a Doutrina da Segurança Nacional. Durante o governo do general Francisco Morales Bermúdez (1975-1980), Cisneros serviu como ministro do Interior. O relato de seu filho sugere que, nessa época, Cisneros agiu como virtual enlace da operação Condor no Peru, o que resultou na irregular expatriação de opositores argentinos que tinham procurado refúgio em território peruano. E, em dezembro de 1981, o presidente Belaúnde Terry o convidou para assumir a pasta da Guerra, mesmo sabendo das desabonadoras preferências político-ideológicas do general, que nunca escondeu sua predileção pelos governos autoritários - especialmente militares.

Nesse contexto, durante o conflito anglo-argentino pelas ilhas do Atlântico Sul, Cisneros, mesmo sem autorização expressa do presidente ou do parlamento peruano, ordenou a transferência - ou mais exatamente o empréstimo - de uma dezena de caças Mirage e de outros sistemas de armamentos sofisticados, bem como de assessores militares, para a Argentina. "A presença de aviōes "MIG" [sic], em território argentino, significaria um efetivo apoio militar do PERU à ARGENTINA", ponderou-se nas fontes consultadas. ${ }^{12}$ Além de afrontar a autoridade formal do país com a inusual decisão, Cisneros acabou usurpando as funções do próprio ministro das Relaçóes Exteriores, que pleiteava uma posição mais equidistante de seu país com relação aos beligerantes. Todavia, a transferência dos caças peruanos para apoiar o dispositivo militar argentino foi muito importante levando-se em consideração a natureza das operaçôes atribuídas à força aérea durante os meses de maio e junho. Além disso, o ministro da Guerra demandou - indiretamente - que a imprensa peruana replicasse a campanha midiática favorável aos argentinos durante o conflito.

\footnotetext{
${ }^{11}$ Sumário Diário de Informaçôes n. 35-E2.1/EME (Confidencial), 27.5.1982. Brasília: Ministério do Exército, SG/CSN/AN.

${ }^{12}$ Sumário Diário de Informaçôes n. 25-E2.1/EME (Confidencial), 12.5.1982. Brasília: Ministério do Exército, SG/CSN/AN. Reitera-se que se tratou da transferência - ou mais exatamente do empréstimo - de uma dezena de caças Mirage - e não de aviōes MiG ou Sukhoi, de fabricação soviética -, da força aérea peruana.
} 
Em numerosas oportunidades a documentação primária consultada confirma o ativismo político-militar de Cisneros. As fontes também ponderam sobre a existência de um possível pacto militar secreto argentino-peruano. Relatam-se as constantes visitas de diplomatas e de adidos militares argentinos ao aeroporto de Lima, que aparentemente era utilizado como base logística para o traslado seguro à Argentina de armamentos procedentes de terceiros países e mercados. E alertaram sobre a possível presença de assessores militares peruanos na regiáo patagônica argentina, próxima do teatro das operaçóes do Atlântico Sul. Em suma, o general Cisneros foi uma peça-chave das relaçôes argentino-peruanas durante os 74 dias de operaçóes militares. Outrossim, enquanto militar hierárquico das forças armadas, parece evidente que Cisneros também acabou ameaçando o processo de transiçáo democrática peruana e colocou em risco a política exterior e a própria segurança internacional do país.

Em consequência, como mencionado na citação acima, em mais de uma oportunidade o presidente Belaúnde Terry foi obrigado a exigir publicamente de seu ministro da Guerra a adoçáo de uma postura mais equidistante diante do conflito anglo-argentino. $\mathrm{O}$ mandatário alertou que oficialmente o Peru era um país que deveria procurar uma solução pacífica e negociada para a crise, e não um país beligerante ou aliado a uma das partes em conflito. Portanto, o general Luis Federico Cisneros Vizquerra teria que interromper suas açôes semiclandestinas e ajustar-se à política oficial do país e da Organização das Naçôes Unidas, que era dirigida por um outro peruano, o secretário-geral Javier Pérez de Cuellar.

Para além do peculiar caso peruano, outros países latino-americanos ofereceram algum tipo de apoio prático às partes beligerantes. O Chile de Pinochet ofereceu alguma colaboração logística e de inteligência aos ingleses, especialmente no que diz respeito à instalação de um poderoso radar na regiáo do Beagle com o propósito de monitorar as açóes da força aérea e da marinha argentina - daí que, em 1998-1999, após ser aprisionado em Londres, Thatcher reivindicasse a libertação do senador chileno, inclusive pela sua colaboração com os ingleses em 1982. O Uruguai colaborou com facilidades logísticas para a realização de traslados humanitários e também para transferências semiclandestinas de material de emprego militar com destino à Argentina. Aparentemente a Venezuela transferiu combustível de alto octanagem e peças de reposição para a força aérea argentina. A ditadura boliviana também teria oferecido apoio prático aos argentinos - cumpre acrescentar que, no caso da manifestação de apoio da aeronáutica boliviana a Buenos Aires, os assessores do ministro do Exército brasileiro ponderassem, com alguma ironia, o seguinte: "dificilmente este apoio sairá do campo político, uma vez que as Forças Armadas bolivianas lutam com o problema de deficiência e obsolescência do seu material". ${ }^{13}$

\footnotetext{
${ }^{13}$ Sumário Diário de Informações n. 42-E2.1/EME (Confidencial), 7.6.1982. Brasília: Ministério do Exército, SG/CSN/AN.
} 
Fora do contexto latino-americano, as fontes primárias consultadas sugerem que um outro país que colaborou ativamente com os argentinos teria sido Israel. A documentação em apreço informa que Tel Aviv teria colocado à disposição do governo de Galtieri a possibilidade de transferir - isto é, a compra-venda - ao menos 24 avióes de combate A-4B Skyhawk, indispensáveis para repor as graves perdas da força aérea argentina e manter as operaçóes contra a força expedicionária britânica. Observe-se que, neste caso, a dimensão econômico-comercial era muito mais relevante que quaisquer consideraçóes político-ideológicas. De fato, em virtude do embargo de armas decretado por numerosos países ocidentais, a Argentina teve que recorrer a mercados clandestinos, pagando muitas vezes o triplo dos preços normais pelos sistemas de armamentos e peças de reposição desejadas - particularmente pelo míssil antinavio francês Exocet.

Finalmente parece pertinente apontar que, no meio do conflito militar anglo-argentino, a população civil das ilhas manteve a expetativa de voltar à soberania britânica (CORBACHO, 2018; MARGHERITIS, 1991). Esse detalhe é importante porque deu consistência à alegação de Londres no sentido de que também lutava pela autodeterminação dos habitantes locais - isto é, dos chamados kelpers. Daí que todo eventual acordo com Buenos Aires deveria respeitar e passar pela consideração dos habitantes civis das ilhas. O posicionamento e as preferências dos habitantes das ilhas Malvinas/Falkland, ainda que fundamentais, estão bem menos presentes na documentação primária consultada na preparação deste ensaio de interpretação.

Cessar-fogo e início da luta pela democratização argentina: inesperadas implicaçóes para o estamento político-militar brasileiro

Nas últimas duas semanas do conflito militar anglo-argentino, e diante da iminente vitória britânica, as fontes consultadas focaram ostensivamente a sua atenção nas prováveis consequências políticas, sociais e estratégicas do acontecimento. Para os fins deste ensaio é particularmente relevante auscultar as percepçóes e interpretaçóes dos analistas do ministério do Exército brasileiro em relação ao devir político-social do vizinho argentino. $\mathrm{O}$ assunto era importante não somente em termos estritamente locais - isto é, domésticos na Argentina -, também foram esboçadas possíveis implicaçôes nas relaçóes bilaterais brasileiro-argentinas (SILVA, 2020). Assim, em 15 de junho, a Apreciação básica dos assessores do ministro do Exército brasileiro ponderava o seguinte:

A luta pela posse de PORTO ARGENTINO (STANLEY), chegou ao seu final.

A imposição de um cessar-fogo provisório, por parte do Cmt das forças britânicas, e a autorização para uma rendição "honrosa", confirmam a disposição da INGLATERRA em 
causar o menor número de perdas possíveis e, também, em não colocar a ARGENTINA em uma situação tão humilhante no contexto interno e externo, permanecendo assim, um canal aberto para as negociações diplomáticas futuras.

O insucesso militar teve suas origens, em grande parte, no despreparo da tropa, constituída, basicamente, de soldados com pouco mais de 3 meses de instrução, sem habilitação técnicomilitar e sem o necessário condicionamento psicológico, contra quem se antepuseram profissionais preparados, maduros e experientes. É de se supor que, reconhecendo tal realidade, o Gen [MARIO BENJAMÍN] MENÉNDEZ tenha aceitado a capitulação, aparentemente em desacordo com o propósito da Junta Militar em persistir na luta, face a indícios obtidos pelos recentes deslocamentos de mais tropas para o sul do país. ${ }^{14}$

Mesmo antes do cessar-fogo provisório e da rendição do destacamento militar argentino nas Malvinas/Falkland, em 14 de junho de 1982, as fontes passaram a tomar nota de um crescente e amplo número de protestos e de açóes coletivas que denunciou aberta e publicamente a "usurpação" dos militares no poder político da nação. Esse questionamento categórico, unânime e inédito desde a implantação do Processo de Reorganização Nacional, em 1976, atingiu em cheio o ethos do governo de Galtieri (SCHENONI; BRANIFF; BATTAGLINO, 2020). E, após a confirmação do fim das operaçóes bélicas ofensivas/defensivas, bem como da destituição-renúncia-passagem para a reserva de Galtieri, todos os principais atores políticos e sociais - bem como parte do próprio estamento militar - passaram a reivindicar uma imediata redemocratização do país. Raúl Alfonsín, líder político da União Cívica Radical, teria denunciado publicamente o seguinte: "O país não merece este Governo, portanto o Governo deve ir-se já, deve cessar a usurpação do Poder, e hoje mesmo se deve pôr em marcha um período de transição civil, até a democracia". ${ }^{15}$ Nesse sentido, a maior parte da literatura sugere que um resultado positivo da derrota militar argentina no conflito do Atlântico Sul foi a precoce reivindicação de uma recomposição política democrática do país (HUNTINGTON, 1994; SURIANO; ÁLVAREZ, 2013).

Com efeito, os Sumários ao ministro do Exército brasileiro redigidos entre 14 de junho e $1^{\circ}$ de julho de 1982 examinam, ponderam e elucubram sobre a crise do governo de Galtieri, sobre as contradiçôes ao interior especificamente do Exército argentino, sobre as divergências entre os comandantes do exército, da marinha e da aeronáutica com relação ao devir da Junta Militar, e também das responsabilidades geradas pela derrota no conflito contra os ingleses no Atlântico Sul. No interlúdio, os analistas do Ministério do Exército brasileiro também vislumbraram - com alguma inquietação - a possibilidade de uma

\footnotetext{
${ }^{14}$ Sumário Diário de Informações n. 46-E2.1/EME (Confidencial), 15.6.1982. Brasília: Ministério do Exército, SG/CS/AN.

${ }^{15}$ Sumário Diário de Informações n. 47-E2.1/EME (Confidencial), 16.6.1982. Brasília: Ministério do Exército, SG/CS/AN.
} 
mudança de regime político no país vizinho. "A derrota militar nas MALVINAS liberou correntes políticas internas, que estavam contidas desde a ascensão ao poder do atual regime", ponderou-se num dos relatórios consultados; acrescentando-se, por exemplo, um alerta no sentido de que "Caso não haja consenso entre os chefes militares, o Governo do Presidente GALTIERI poderá perder o controle da situação e provocar um grave enfrentamento entre as facçôes (inclusive os peronistas e esquerdistas) que buscam se apropriar da situação para alcançar o poder."16

Fundamentados nos relatórios encaminhados pelo adido militar brasileiro em Buenos Aires, os assessores do ministro Walter Pires informaram da renúncia, da destituição e da passagem para a reserva de Galtieri. Segundo as fontes, o afastamento de Galtieri se deveu a que ele "estava sem condiçóes para negociar a cessação das hostilidades, aceitando as imposiçóes inglesas, uma vez que foi o principal responsável pela decisão de ocupar as MALVINAS." ${ }^{17}$ Em uma tormentosa reuniāo dos oficiais-generais do Exército argentino, em 17 de junho, e diante da tentativa de Galtieri de dar continuidade ao conflito com os ingleses - mesmo depois da derrota na batalha das Malvinas/Falkland - seus companheiros de farda determinaram a queda do ditador. Cumpre acrescentar que a queda de Galtieri foi recebida com certo alívio pelos assessores do ministro do Exército brasileiro, devido à crescente intransigência e à dependência daquele em relação aos soviéticos.

Também se informou da instalaçáo, em $1^{\circ}$ de julho de 1982, de um governo exclusivamente do Exército e comandado pelo general (retirado) Reynaldo Benito Antonio Bignone Ramayón. A tarefa básica do governo de Bignone seria a devolução do poder aos civis e a redemocratização do país, no prazo de um ano; bem como confirmar a rendição das forças argentinas nas ilhas e a redefinição da política econômico-social do país. As fontes consultadas também destacaram os esforços de pacificação ao interior da Junta Militar, o ressurgimento dos partidos políticos e das lideranças da oposiçáo, as vicissitudes do retorno ao país do destacamento até entáo presente nas ilhas - aproximadamente 11 mil soldados (LORENZ, 2014) - e da espinhosa questáo dos "desaparecidos" durante a feroz ditadura implantada no país desde 1976 (NOVARO; PALERMO, 2007). Destarte, "o conflito das MALVINAS deixou a fase das operaçôes militares para se situar no plano político, uma vez que a derrota militar argentina gerou uma crise interna, ainda em desenvolvimento", apontou-se no último dos relatórios consultados. ${ }^{18}$

Observe-se que o questionamento e a denúncia opositora de uma "usurpação" do poder político pelos militares argentinos registrada na documentação consultada implica-

\footnotetext{
${ }^{16}$ Sumário Diário de Informaçôes n. 47-E2.1/EME (Confidencial), 16.6.1982. Brasília: Ministério do Exército, SG/CS/AN.

${ }^{17}$ Sumário Diário de Informaçôes n. 49-E2.1/EME (Confidencial), 18.6.1982. Brasília: Ministério do Exército, SG/CS/AN.

${ }^{18}$ Sumário Diário de Informaçôes n. 59-E2.1/EME (Confidencial), 2.7.1982. Brasília: Ministério do Exército, SG/CS/AN.
} 
vam, decerto, uma crítica implícita da legitimidade dos governos que formaram parte do Processo de Reorganização Nacional. Evidentemente, a suposta "usurpaçáo" somente poderia ser sarada e superada com uma mudança de regime político de orientação democrática. Todavia, no marco conceitual da "terceira onda" de democratização de Huntington (1994), mudanças de regime em outros países do Cone Sul - inclusive no Brasil - não poderiam ser descartadas.

Sob a perspectiva dos ingleses, a vitória militar no Atlântico Sul foi, evidentemente, recebida com júbilo e exaltação nacionalista. A primeira-ministra Margaret Thatcher anunciou que, no cenário pós-bélico, o Reino Unido não estaria disposto a discutir ou negociar a soberania britânica nas ilhas com a Argentina. Tampouco seria admitida a possibilidade de aceitar uma missão de paz da ONU ou uma força interamericana de paz da OEA nos territórios britânicos daquela região do planeta. Todavia, no sucessivo, o princípio da autodeterminação dos povos - nesse caso dos kelpers - teria que ser considerado na inserçấo internacional do referido território e no autogoverno administrativo interno (HEWER, 2013; MARGHERITIS, 1991).

Agora sabemos que a vitória inglesa também acabou favorecendo eleitoralmente o Partido Conservador, nas eleiçôes gerais de junho de 1983. Na ocasião, Thatcher, também conhecida como a "Dama de Ferro", venceu facilmente os opositores, erigindo-se numa popular figura em círculos de orientaçáo direitista e neoliberal na Europa e alhures.

Seja como for, para uma parte considerável da opiniáo pública mundial - inclusive para a maior parte da opiniáo pública brasileira - a questão das Malvinas/Falkland continuou sendo, essencialmente, um conflito Norte-Sul, fortemente correlacionado ao colonialismo e ao imperialismo - semelhante ao observado em Gibraltar. Daí que essa disputa territorial no continente americano continue em aberto até nossos dias (BLAIR, 2019; GUBER, 2013). ${ }^{19}$

\section{Considerações finais}

Em 3 de junho de 1982, um bombardeiro Avro Vulcan, da Real Força Aérea britânica, foi obrigado a realizar um pouso de emergência no Rio de Janeiro. Na ocasião, o comandante do avião informou que tinha decolado da ilha de Ascensão para realizar uma missão de ataque nas ilhas Malvinas/Falkland. Contudo, no meio da rota, o aviáo teria experimentado problemas técnicos e, com autorização superior, teria sido decidida sua internação no Brasil, um país neutral no conflito anglo-argentino. Na documentaçáo consultada, o episódio em

\footnotetext{
${ }^{19}$ Cumpre acrescentar que, em março de 2018, as autoridades inglesas das ilhas Malvinas/Falkland concordaram em homenagear as vítimas e avançar na identificação dos soldados argentinos enterrados desde o conflito (CUÉ, 2018).
} 
referência foi considerado nos seguintes termos: "A ameaça de violação de nossos espaços aéreo, marítimo e terrestre [...] é materializada, pela primeira vez, com o pouso de aeronave VULCAN de nacionalidade inglesa". ${ }^{20}$

Efetivamente, o incidente com o Vulcan foi um dos poucos episódios que envolveram ou atingiram diretamente a soberania brasileira durante os 74 dias de hostilidades anglo-argentinas. Entretanto, a documentação primária consultada sugere que algumas outras hipóteses foram consideradas pelas autoridades militares - especificamente do Exército brasileiro -, dentre elas: a realização de operaçóes de busca e salvamento marítimo, a internação de navios de guerra e suas tripulaçôes, e a interceptação de avióes civis e militares. Com efeito, um outro exemplo de aparente tentativa de violaçáo do espaço aéreo brasileiro durante o conflito anglo-argentino foi o caso da detenção forçosa de um avião civil da empresa Cubana de Aviación, em 9 de abril de 1982, que transportava de forma clandestina o então embaixador cubano na Argentina, Emílio Aragonés Navarro.

Observe-se que, mesmo neutral, o governo de Figueiredo aceitou assumir os interesses argentinos na embaixada brasileira em Londres. Daí que algumas informaçóes - sobretudo de natureza humanitária e do direito internacional da guerra, como a identificaçáo de navios-hospitais - fossem encaminhadas pelos canais diplomáticos brasileiros, inclusive pelas aditâncias militares. Todavia, parece apropriado acrescentar que a neutralidade brasileira foi bastante benevolente para o lado argentino do conflito. Nessa linha, avióes militares - Bandeirantes -, armas e muniçôes, combustível, créditos, facilidades logísticas para a realizaçâo de transferências mais ou menos clandestinas de material de emprego militar procedente de terceiros países, peças de reposição, dentre outras alternativas, foram concedidas pelas autoridades brasileiras com intuito de reforçar o dispositivo militar do governo de Galtieri (LAFER, 1984; PINHEIRO, 1986). Destarte, uma pesquisa específica poderia se encarregar de esclarecer as reaçôes britânicas durante o conflito diante dessas iniciativas brasileiras - isto é, de um país teoricamente neutral - favoráveis ao lado argentino.

De forma mais abrangente, parece pertinente concluir que o presente artigo é uma contribuição ao debate sobre um dos conflitos militares mais insólitos do último quartel do século XX (ALEIXO, 1991). Um conflito que enfrentou a força-tarefa mais vultuosa dos ingleses desde o fim da Segunda Guerra Mundial, contra o operativo argentino mais considerável desde a época da Guerra da Tríplice Aliança ou do Paraguai. Observe-se que na literatura especializada o conflito do Atlântico Sul foi considerado desde diferentes perspectivas teóricas e metodológicas. Para alguns, tratou-se de um conflito colonialista, outros o consideraram como uma disputa territorial militarizada, e não faltam autores que destacam a questão da correlação entre regime político e política externa. Além disso, está a questão do impacto da Guerra Fria - ou mais exatamente da teoria dos conflitos Oeste-Oeste (PÉREZ LLANA, 1984; MUÑOZ, 1984; RECORD, 1982).

\footnotetext{
${ }^{20}$ Sumário Diário de Informaçôes n. 40-E2.1/EME (Confidencial), 3.6.1982. Brasília: Ministério do Exército, SG/CS/AN.
} 
O presente ensaio de interpretação foi realizado a partir de pesquisa com fontes militares brasileiras, disponíveis no Arquivo Nacional. A pesquisa com fontes (militares) primárias permite acrescentar informaçóes ao conhecimento científico sobre o problema-objeto, especialmente no caso dos estudos de segurança internacional, da história das relaçóes internacionais e da história militar contemporânea. Destarte, no quadragésimo aniversário do conflito anglo-argentino - isto é, de um distanciamento temporal que, em teoria, permitiria a desclassificação de toda a documentação secreta e confidencial disponível nos arquivos civis e militares brasileiros sobre o problema-objeto -, acredita-se que uma nova safra de pesquisas científicas poderia estar emergindo. E, nesse sentido, o resgate e a pesquisa fundamentada em fontes militares parece ser uma boa alternativa para auscultar o pensamento e os desdobramentos do conflito anglo-argentino no estamento militar brasileiro.

\section{Fontes documentais}

SUMÁRIO Diário de Informações n. 5-E2.1/EME (Confidencial), 12 abr. 1982. Brasília: Ministério do Exército, Acervo da Secretaria Geral do Conselho de Segurança Nacional, Coordenação Regional do Arquivo Nacional no Distrito Federal.

SUMÁRIO Diário de Informações n. 7-E2.1/EME (Confidencial), 14 abr. 1982. Brasília: Ministério do Exército, Acervo da Secretaria Geral do Conselho de Segurança Nacional, Coordenação Regional do Arquivo Nacional no Distrito Federal.

SUMÁRIO Diário de Informaçóes n. 8-E2.1/EME (Confidencial), 15 abr. 1982. Brasília: Ministério do Exército, Acervo da Secretaria Geral do Conselho de Segurança Nacional, Coordenação Regional do Arquivo Nacional no Distrito Federal.

SUMÁRIO Diário de Informações n. 12-E2.1/EME (Confidencial), 22 abr. 1982. Brasília: Ministério do Exército, Acervo da Secretaria Geral do Conselho de Segurança Nacional, Coordenação Regional do Arquivo Nacional no Distrito Federal.

SUMÁRIO Diário de Informações n. 15-E2.1/EME (Confidencial), 27 abr. 1982. Brasília: Ministério do Exército, Acervo da Secretaria Geral do Conselho de Segurança Nacional, Coordenação Regional do Arquivo Nacional no Distrito Federal.

SUMÁRIO Diário de Informaçóes n. 18-E2.1/EME (Confidencial), 30 abr. 1982. Brasília: Ministério do Exército, Acervo da Secretaria Geral do Conselho de Segurança Nacional, Coordenação Regional do Arquivo Nacional no Distrito Federal.

SUMÁRIO Diário de Informações n. 25-E2.1/EME (Confidencial), 12 maio 1982. Brasília: Ministério do Exército, Acervo da Secretaria Geral do Conselho de Segurança Nacional, Coordenação Regional do Arquivo Nacional no Distrito Federal. 
SUMÁRIO Diário de Informações n. 35-E2.1/EME (Confidencial), 27 maio 1982. Brasília:

Ministério do Exército, Acervo da Secretaria Geral do Conselho de Segurança Nacional, Coordenação Regional do Arquivo Nacional no Distrito Federal.

SUMÁRIO Diário de Informaçôes n. 40-E2.1/EME (Confidencial), 3 jun. 1982. Brasília: Ministério do Exército, Acervo da Secretaria Geral do Conselho de Segurança Nacional, Coordenação Regional do Arquivo Nacional no Distrito Federal.

SUMÁRIO Diário de Informações n. 42-E2.1/EME (Confidencial), 7 jun. 1982. Brasília: Ministério do Exército, Acervo da Secretaria Geral do Conselho de Segurança Nacional, Coordenação Regional do Arquivo Nacional no Distrito Federal.

SUMÁRIO Diário de Informaçóes n. 44-E2.1/EME (Confidencial), 9 jun. 1982. Brasília: Ministério do Exército, Acervo da Secretaria Geral do Conselho de Segurança Nacional, Coordenação Regional do Arquivo Nacional no Distrito Federal.

SUMÁRIO Diário de Informaçôes n. 46-E2.1/EME (Confidencial), 15 jun. 1982. Brasília: Ministério do Exército, Acervo da Secretaria Geral do Conselho de Segurança Nacional, Coordenação Regional do Arquivo Nacional no Distrito Federal.

SUMÁRIO Diário de Informações n. 47-E2.1/EME (Confidencial), 16 jun. 1982. Brasília: Ministério do Exército, Acervo da Secretaria Geral do Conselho de Segurança Nacional, Coordenaçáo Regional do Arquivo Nacional no Distrito Federal.

SUMÁRIO Diário de Informaçôes n. 49-E2.1/EME (Confidencial), 18 jun. 1982. Brasília: Ministério do Exército, Acervo da Secretaria Geral do Conselho de Segurança Nacional, Coordenação Regional do Arquivo Nacional no Distrito Federal.

SUMÁRIO Diário de Informaçôes n. 59-E2.1/EME (Confidencial), 2 jul. 1982. Brasília: Ministério do Exército, Acervo da Secretaria Geral do Conselho de Segurança Nacional, Coordenação Regional do Arquivo Nacional no Distrito Federal.

\section{Referências}

ALEIXO, José Carlos Brandi. Alternativas de solução pacífica para as Malvinas. Contexto Internacional, Rio de Janeiro, v. 13, n. 2, p. 205-226, 1991.

ARMONY, Ariel. La Argentina, los Estados Unidos y la cruzada anticomunista en América Central, 1977-1984. Buenos Aires: Universidad Nacional de Quilmes, 1999.

BLAIR, James J. A. South Atlantic universals: science, sovereignty and self-determination in the Falkland Islands (Malvinas). Tapuya: Latin American Science, Technology and Society, Puebla, v. 2, n. 1, p. 220-236, 2019. 
BRATTON, Patrick; THIES, Wallace. When Governments Collide in the South Atlantic: Britain coerces Argentina during the Falkland War. Comparative Strategy, Reading, v. 30, n. 1, p. 1-27, 2011.

CISNEROS, Renato. La distancia que nos separa. Lima: Planeta, 2015.

CORBACHO, Alejandro L. 74 days under the Argentine flag: the experiences of occupation during the Falklands/Malvinas war. Documento de Trabalho n. 682, Buenos Aires: CEMA, 2018. Disponível em: www.cema.edu.ar/publicaciones/doc_trabajo.html. Acesso em: 18 jul. 2020.

CUÉ, Carlos E. Las tumbas con nombre, un cierre de la guerra de Malvinas 36 años después. El País, 27 mar. 2018. Disponível em: https://elpais.com/internacional/2018/03/26/ argentina/1522078167_708033.html. Acesso em: 16 jul. 2020.

DAVID, Charles-Philippe. A guerra e a paz. Abordagens contemporâneas da segurança e da estratégia. Lisboa: Piaget, 2001.

ESCUDÉ, Carlos. El nacionalismo territorial argentino. In: PERINA, Rubén; RUSSELL Roberto (orgs.). Argentina en el mundo (1973-1987). Buenos Aires: Grupo Editor Latinoamericano, 1988. p. 241-262.

GUBER, Rosana. Como un cierre. Igualdad, honor y amistad entre contendientes directos, después de la Malvinas. Tabula Rasa, Bogotá, n. 19, p. 11-27, 2013.

HALLIDAY, Fred. The Making of the Second Cold War. Londres: Verso, 1986.

HEWER, Christopher. The Falkland/Malvinas dispute: a contemporary battle between history and memory. Global Discourse, Bristol, v. 3, n. 1, p. 144-150, 2013.

HUNTINGTON, Samuel. A terceira onda de democratização. São Paulo: Ática, 1994.

JAGUARIBE, Helio. Reflexóes sobre o Atlântico Sul. América Latina e Brasil ante a desarticulação do sistema interamericano. Rio de Janeiro: Paz e Terra, 1985.

KREPP, Stella Paresa. Between the Cold War and the Global South: Argentina and Third World Solidarity in the Falklands/Malvinas Crisis. Estudos Históricos, Rio de Janeiro, v. 30, n. 60, p. 141-160, 2017.

LAFER, Celso. La política exterior brasileña y la crisis en el Atlántico Sur: una evaluación. In: RUSSELL, Roberto (org.). América Latina y la Guerra del Atlántico Sur. Experiencias y desafíos. Buenos Aires: Editorial de Belgrano, 1984. p. 125-136.

LEBOW, Richard Ned. Miscalculation in the South Atlantic: the origins of the Falkland War. Journal of Strategic Studies, Leeds, v. 6, n. 1, p. 5-35, 1983.

LIVINGSTONE, Grace. Oil and British Policy towards the Falkland/Malvinas Islands. Revista SAAP, Buenos Aires, v. 14, n. 1, p. 131-155, 2020.

LORENZ, Federico. Gran Malvina. Una mirada a la experiencia bélica desde los testimonios de sus oficiales. Anuario Colombiano de Historia Social y de la Cultura, Bogotá, v. 41, n. 2, 
p. 225-257, 2014.

MARES, David; BERNSTEIN, Steve. El uso de la fuerza en las relaciones interestatales de América Latina. In: DOMÍNGUEZ, Jorge (org.). Seguridad internacional, paz y democracia en el Cono Sur. Santiago: Flacso e Diálogo Interamericano, 1998. p. 49-79.

MARGHERITIS, Ana. Os recursos energéticos das Ilhas Malvinas e sua relação com o conflito anglo-argentino. Contexto Internacional, Rio de Janeiro, v. 13, n. 1, p. 111-132, 1991.

MONETA, Carlos. El conflicto de las islas Malvinas en el contexto de la política exterior argentina. In: RUSSELL, Roberto (org.). América Latina y la Guerra del Atlántico Sur. Experiencias y desafios. Buenos Aires: Editorial de Belgrano, 1984. p. 1-59.

MUÑOZ, Heraldo. Efectos y lecciones del conflicto de las Malvinas. In: RUSSELL, Roberto (org.). América Latina y la Guerra del Atlántico Sur. Experiencias y desafios. Buenos Aires: Editorial de Belgrano, 1984. p. 193-208.

NOVARO, Marcos; PALERMO, Vicente. A ditadura militar argentina 1976-1983. São Paulo: Edusp, 2007.

ORREGO VICUÑA, Francisco. El elusivo entendimiento entre América Latina y los Estados Unidos. In: RUSSELL, Roberto (org.). América Latina y la Guerra del Atlántico Sur. Experiencias y desafios. Buenos Aires: Editorial de Belgrano, 1984. p. 157-173.

PÉREZ LLANA, Carlos. La política exterior de la Argentina post-Malvinas. In: RUSSELL, Roberto (org.). América Latina y la Guerra del Atlántico Sur. Experiencias y desafios. Buenos Aires: Editorial de Belgrano, 1984. p. 61-99.

PHILIP, George. British involvement in Latin America. In: PERRY William; WEHNER, Peter (orgs.). The Latin American Policies of U.S. Allies. Nova York: Praeger Publishers, 1985. p. 31-54.

PINHEIRO, Letícia. A omissão diplomática. A diplomacia brasileira na Guerra das Malvinas. Política e Estratégia, São Paulo, v. IV, n. 4, p. 587-604, 1986.

RAPOPORT, Mario. La posición internacional de la Argentina y las relaciones argentinosoviéticas. In: PERINA, Rubén; RUSSELL Roberto (orgs.). Argentina en el mundo (19731987). Buenos Aires: Grupo Editor Latinoamericano, 1988. p. 171-207.

RECORD, Jeffrey. The Falkland War. The Washington Quarterly, Washington, v. 5, n. 4, p. 43-51, 1982.

ROETT, Riordan. La guerra del Atlántico Sur: una perspectiva de Estados Unidos. In: RUSSELL, Roberto (org.). América Latina y la Guerra del Atlántico Sur. Experiencias y desafios. Buenos Aires: Editorial de Belgrano, 1984. p. 137-148.

RUSSELL, Roberto. Argentina y la política exterior del régimen autoritario (1976-1983): una evaluación preliminar. In: PERINA, Rubén; RUSSELL Roberto (orgs.). Argentina en el 
mundo (1973-1987). Buenos Aires: Grupo Editor Latinoamericano, 1988. p. 99-128.

SANTOS, Eduardo dos. Entre o Beagle e as Malvinas. Conflito e diplomacia na América do Sul. Brasília: Fundação Alexandre de Gusmão, 2016.

SCHENONI, Luis L.; BRANIFF, Sean; BATTAGLINO, Jorge. Was the Malvinas/Falklands a Diversionary War? A Prospect-Theory Reinterpretation of Argentina's Decline. Security Studies, Oxford, v. 29, n. 1, p. 34-63, 2020.

SILVA, Álvaro Costa. Diverse images, reverse strategies: Brazilian foreign ministers' perceptions and the Brazil-Argentina rapprochement (1974-1985). Revista Brasileira de Politica Internacional, Brasília, v. 63, n. 1, 2020, e006.

SURIANO, Juan; ÁLVAREZ, Eliseo. 505 días. La primera transición a la democracia. De la rendición de Malvinas al triunfo de Alfonsin. Buenos Aires: Sudamericana, 2013.

TULCHIN, Joseph S. A Guerra das Malvinas: conflito inevitável que nunca deveria ter ocorrido. Politica e Estratégia, São Paulo, v. IV, n. 4, p. 605-622, 1986.

VACS, Aldo. Los socios discretos. El nuevo carácter en las relaciones entre la Argentina y la Unión Soviética. Buenos Aires: Sudamericana, 1984.

VERBITSKY, Horacio. Malvinas: la última batalla de la Tercera Guerra Mundial. Buenos Aires: Sudamericana, 2002.

WALTZ, Kenneth. Theory of International Politics. Nova York: McGraw-Hill, 1979. 